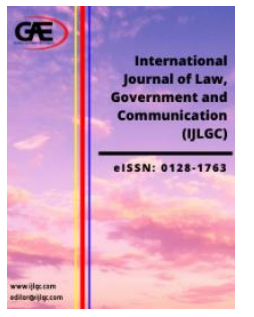

\author{
INTERNATIONAL JOURNAL OF LAW, \\ GOVERNMENT AND COMMUNICATION \\ (IJLGC) \\ $\underline{\text { www.ijlgc.com }}$
}

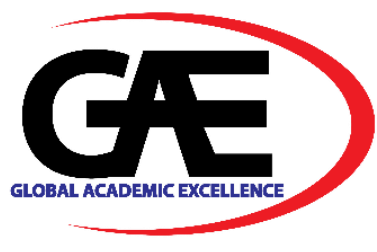

\title{
SINGLE-USE PLASTIC: REDUCE OR IGNORE
}

\author{
Noor Aziah Abdullah ${ }^{1 *}$, Cheang Hui ${ }^{2}$, Mohd Harryzman Harun ${ }^{3}$ \\ $1 \quad$ Faculty of Art \& Science, Universiti Utara Malaysia \\ Email: nooraziah@uum.edu.my \\ 2 Faculty of Art \& Science, Universiti Utara Malaysia \\ Email: cheangh097@gmail.com \\ 3 Faculty of Art \& Science, Universiti Utara Malaysia \\ Email: harry@uum.edu.my \\ * Corresponding Author
}

\section{Article Info:}

Article history:

Received date: 10.10 .2021

Revised date: 15.11 .2021

Accepted date: 25.11 .2021

Published date: 01.12.2021

\section{To cite this document:}

Abdullah, N. A., Cheang, H., \& Harun, M. H. (2021). Single-Use Plastic: Reduce Or Ignore. International Journal of Law, Government and Communication, 6 (26), 120-126.

DOI: $10.35631 /$ IJLGC.626010.

This work is licensed under CC BY 4.0

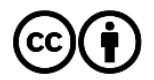

\begin{abstract}
:
Malaysia is one of the worst countries overflowed with tonnes of single-use plastic waste in Asia. Our reliance on these plastics means we are accumulating waste at a staggering rate. The users flavor single-use plastic due to the fact durable, cheap, easy to obtain, and makes packaging convenient. Single-use plastic packaging such as plastic cups and straws, wrapper, plastic cutlery, and plastic bags are used by humans every day. The overuse of single-use plastic harmed the ecosystem, human health, and the image of Malaysia. Therefore, this study aims to create public awareness about the seriousness of single-use plastic waste's effect on their living environment and encourage the audiences to reduce using the these-use plastic product. An in-depth interview has conducted with two environmental-based experts and an environmental organization to understand more information about the single-use plastic issue in Malaysia. A few alternative materials to replace single-use plastic has been introduced: edible cutlery, bio-degradable grocery bags, paper bag, bamboo, and paper straw. Hence, the public must be concerned about single-use plastic issues to reduce the unnecessary usage of plastic, which will increase the burden on the environment. This study will benefit the Government and agencies related to how to solve the single-use plastic issue.
\end{abstract}

Keywords:

Single-Use Plastic, Environmental, Pollution, Awareness, Documentary

\section{Introduction}

Plastic waste has been contributed to environmental issues past a few decades ago. Malaysia has been rated as one of the world's worst for plastic pollutions, as a study estimated Malaysia had produced 0.94 million tons of plastic waste in the world. Plastic pollution is a serious 


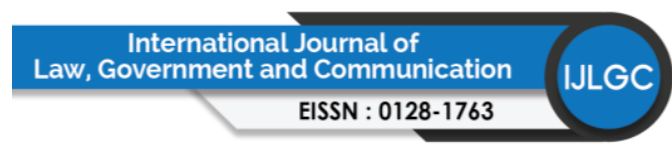

Volume 6 Issue 26 (December 2021) PP. 120-126

DOI 10.35631/IJLGC.626010

environmental issue that always is ignored by the public, especially domestic plastic waste. New Straits Times (2019), Minister of Environment Teo Bee Yin, said Malaysia had become the dumping ground for the world's plastic waste. Therefore, some people or organizations will take the step of open burning or buried underground whose single-use plastic product solves the undegradable problem. Those non-recyclable plastic scraps will send back to the developed countries that sent them here.

Single-use plastic products are part of the demand in daily human life since they were introduced to the public. People practically use plastic products every day under any circumstance, such as plastic to put sandwiches, boba tea, plastic straw, and plastic bottle. Single-use plastic product is non-biodegradable which the product will remain the same in the earth even after 100 years later. Nevertheless, it accelerates the emission of toxic chemicals to humans and the environment, such as respiratory problems, food chains, and even growing more pollution such as water, air pollution.

\section{Problem Statement}

Malaysia becomes Asia's most prominent plastic consumer compared to the other five countries in Asia reported by WWF based on recent news on New Straits Times. The WWF report stated Malaysia produced 60 percent, which is about 8 million tonnes of plastic, into the world's oceans each year. The overuse of single-use plastic through food and beverage packaging's such as food delivery and boba milk tea trend in Malaysia has failed to collect and dispose of the waste without a proper plastic waste infrastructure. The WWF coordinator urged the Malaysian Government to take adequate steps to reduce the use of single-use plastic.

Malaysia is one of the eighth-worst countries worldwide flooded with plastic waste produced by the resident and other country waste based on an academic journal Science. It is estimated Malaysia has produced almost one million tons of mismanaged plastic waste in 2010, which 0.14 to 0.37 million tonnes may have washed into the oceans. The most common single-use plastic waste is plastic straws, plastic bags, and plastic bottles on the roadside, seashores, and dumpsites.

The factors of people using single-use plastics are because easy to get, durable, cheap, and convenient. It is an ideal material for single-use food and non-food packaging, which can be throw after use. The mass production of plastic took only a short time to complete the process. Thus, making a new plastic is lower than recycling plastic due to the recycling process being complicated. (Kramer. S, 2016) Plastics are light and durable, convenient for carrying solid and liquid products and easy to throw away after using them.

The overuse of single-use plastic is destroying the environment, society, and the reputation of Malaysia. The non-biodegradable single-use plastic will enter the ground, air, and water which causes water pollution, climate change, and animal extinction that destroys the ecosystem. Meanwhile, the area residents will have health issues such as respiratory disease due to microplastic released by plastic products (Luo. K, 2016). Besides, the wildlife animals will accidentally eat the "food-like" plastic because they cannot identify the difference between plastic and food (Two Oceans Aquarium, 2019). The overflow of single-use plastic waste in Malaysia had gained the title of "Asian worst plastic polluters" by WWF, damaging the country's reputation. 


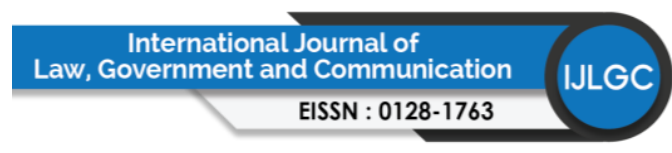

Volume 6 Issue 26 (December 2021) PP. 120-126

DOI 10.35631/IJLGC.626010

The Government and Non-Government organizations (NGOs) should take proactive action to raise awareness among consumers to reduce the use of single-use plastic. A study by IPSOS Malaysia revealed that Malaysians (56\%) are aware and concerned about the single-use plastic issue in Malaysia. The people understand the current circumstances of plastic product is damaging the living system. However, the IPSOS Malaysia study stated that most Malaysians $(60 \%$ and $50 \%)$ are willing to pay more for products that harm the environment and RM0.20 for the use of plastic bags. This shows people are aware of the current situation of single-use plastic. Still, they disregard the issue due to personal benefits because single-use plastic is convenient to get and use.

\section{Research Objective (s)}

There are two main objectives to achieve in this study:

i. To create public awareness about the seriousness of single-use plastic waste's effect on their living environment.

ii. To encourage the audiences to reduce the habit of using single-use plastic products.

\section{Literature Review}

According to the American Chemistry Council, Plastics, also called polymers, are produced by converting natural products or synthesizing primary chemicals from oil, natural gas, or coal. Firstly, plastic was invented by Alexander Parkes in 1856; thus, artificial plastic with no natural ingredients was invented by Leo Baekeland in 1907. The production of plastic is mainly reliant on fossil hydrocarbons, which are non-renewable resources (Giacovelli, 2018). Single-use plastic becomes the first choice for people to use in daily life. The single-use plastic products included grocery bags, food packaging, bottles, straws, and cutlery, which are more convenient for everyday activities.

Kramer.S (2016) states that single-use plastic is an ideal material for single-use food and nonfood packaging that can be throw after using it once. The mass production of plastic took only a short time to complete the process. Thus, making a new plastic is lower than recycling the plastic because the recycling process is complicated (Kramer. S, 2016). Single-use plastic material is light and durable, which is very convenient for carrying solid and liquid products. It helps to preserve the freshness and shape of products and hygiene from external germs. Plus, the packaging is one way to attract consumers and convey the information and instruction of the products, such as expiry and manufacture date, materials, and ingredients.

A survey from IIUM (2017) stated that people with higher education and income and older are more willing to participate in no plastic bag campaign than their counterparts. The survey found that people cannot distinguish the pros and cons of protecting the environment. It is hard to change people's behavior in a short time. Although people realize that they must preserve the atmosphere before it's too late, this knowledge is hard to translate into action and behavior.

According to an article from Frontiers in Psychology, people tend to value personal over collective rewards. It's due to the eager enjoy their life in real-time rather than thinking about the future. Therefore, people most likely prefer immediate over delayed rewards. 


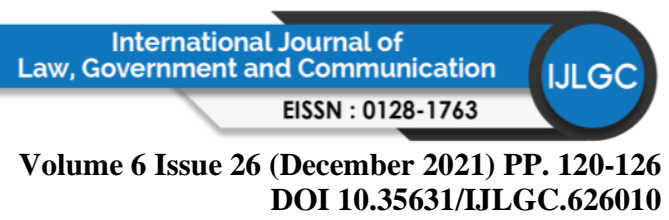

\section{The Impact}

\section{Environment}

Single-use plastics waste is an environmental threat, is composed of major toxic pollutants, and has excellent harm toward the air, water, and land pollution. Single-use plastic products are mainly made with poisonous chemicals and non-biodegradable components such as Polyvinyl chloride (PVC), Bisphenol-A(BPA), and Phthalates. Those chemical substances are known to be harmful to the human body and marine life and land animals, leading to health problems and taking more than a thousand years to decompose the plastic.

\section{Health}

The emission of toxic gases will damage the human respiratory system as days goes by. Based on the journal of Procedia Environmental Sciences, the burning of plastic waste will increase the risk of heart disease, aggravates respiratory ailments such as asthma and emphysema and cause rashes, nausea, or headaches, and damages the nervous system (Verma, Vinoda, Papireddy, \& Gowda, 2016). Besides, long-term exposure to air pollution will worsen respiratory system diseases, leading to lung cancer.

\section{Image}

Tourism is the third contributor to the Malaysian economy; a lousy image will affect tourists' perception. According to The Star Online, Malaysia has been rated one of the world's worst countries for plastic pollution (Balasegaram, 2019). Hence, Malaysia having the title as "worst countries for plastic pollution in Asia" that entitle by WWF with photos, videos, and statistics as evidence. Thus, some tourists will refuse to travel to Malaysia because of the polluted situation and leave negative assumptions.

\section{Methodology}

Qualitative methods are used to understand human behaviors, perspectives, feelings, experiences, and everything that happens in their lives (Othman Lebar 2014). This study aims to create public awareness about the seriousness of single-use plastic waste's effect on their living environment. Together, to encourage the audiences to reduce the habit of using the single-use plastic product. Hence, the research uses an entirely qualitative methodology to achieve the objectives of the study. In-depth interviews, observation, and document analysis were adopted in this study. The informants are Senior Lecturer of Philosophy, Civil and Earth Resources Engineering Dr. Chong Khai Lin, Co-founder of Trash Hero Kuala Lumpur, Amy Popovich, Nabila Akhyar, and Yanuar Ibrahim, who is the participants of the Trash Hero event. Two of the informants were chosen based on their expertise and knowledge in single-use plastic. The observation was done at public areas such as supermarkets, restaurants, shopping complexes, and parks.

\section{Results}

Single-use plastic is one of the crucial issues that everyone needs to be confirmed and alert to. The most common issue of single-use plastic is the leading creator or the main contributor to pollution is more to the marine. So why did this happen? It is not because of the plastic itself, but more to the user's behavior. Nevertheless, if we provide enough education or awareness to the person, we need to throw the waste into the correct place, then single-use plastic would not become a big issue. People need to understand the meaning of the 3R Concept. It starts with 


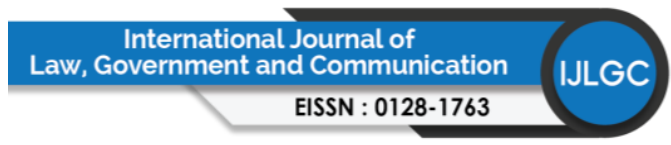

Volume 6 Issue 26 (December 2021) PP. 120-126

DOI 10.35631/IJLGC.626010

Reduce, Reuse, and then Recycled. There are few reasons people prefer plastic rather than paper-first; it's durable, cheap, leakage-proof, and flexible.

For example, most of the packaging is made of plastic such as bread or Nestum, for our breakfast. In our life, it's tough for us to avoid that. When we say about the packaging, most of us prefer that something transparent be visible. Therefore, we still need some parts of it to be plastic. Malaysian consumer behavior is eager to see the content inside the packaging rather than read a label at the back of the packaging. According to Trash Hero Kuala Lumpur (NGO), they regularly collect about $150 \mathrm{~kg}$ of trash from single-use plastic waste during campaigns in areas such as beaches, theme parks, and other public places. The impact of it if we didn't have appropriate management or handling methods, will harm our environment. Why? Plastic cannot be disposed of; it's not biodegradable, it will stay there forever. Even you put it there for one year; the quality is still the same; plastic still is there.

Thus, when people decide to use one thing, they must think if it is only for one time or multiple times. Therefore, the pros and cons we need to be balancing since we can't stop. The solution for this issue is as a consumer we must take the first step. A few alternative materials to replace single-use plastic has been introduced: edible cutlery, bio-degradable grocery bags, paper bag, bamboo, and paper straw. The Government has launched the roadmap towards no single-use plastic start 2018 until 2030. The consumer should reduce buying mineral water or pack sold, and for grocery, consumers should bring their shopping bags. Carrying own bottles and food packaging is the most effective solution to avoid single-use plastic. Instead of using a plastic bag to put food in the freezer, we should use a small container that can be reused.

\section{Discussion}

Single-use plastics are a glaring example of the problems with throwaway culture. Instead of investing in quality goods that will last, we often prioritize convenience over durability and consideration of long-term impacts. Human is the creator of single-use plastic issue, not the products itself. Single-use plastics waste is an environmental threat, is composed of major toxic pollutants, and has excellent harm toward the air, water, and land pollution. Reducing plastic use is the most effective means of avoiding this waste. Hence, cooperation between consumers and Government is essential. The Initiative taken by Government which has launched the Roadmap towards no single-use plastic start 2018 to 2030, shows the seriousness of this issue. One of the significant actions taken is to ban single-use plastic every Saturday at grocery outlets. Customers have to pay for it if they still insist. The effect of this single-use plastic waste will cause harm to the environment, health, and image of the country. The nongovernment organization (NGO) that focuses on single-use plastic waste does its campaign by inviting volunteers to clean up public areas such as beaches, parks, and streets.

\section{Conclusion}

Our plastic addiction is having a devastating impact on our oceans, our wildlife, and our health. The $3 \mathrm{R}$ campaigns, namely Reduce, Reuse, and Recycled must be understood and followed by Malaysians to reduce the use of plastic to be achieved. All the efforts made by the Government will not be achieved without the cooperation of all parties. This issue must be given serious attention for the sake of future generations. 


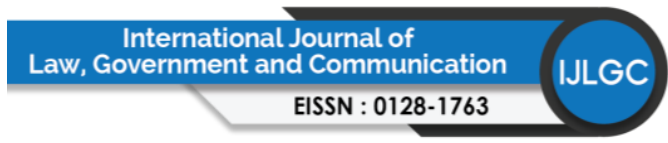

Volume 6 Issue 26 (December 2021) PP. 120-126

DOI 10.35631/IJLGC.626010

\section{References}

American Chemistry Council. (2005). How plastics are made. Plastics Industry Producer Statistics Group. https://plastics.americanchemistry.com/How-Plastics-Are-Made/

Abdullah., N., T. (2018). The huge problem of plastic waste in M'sia. Retrieved from https://www.malaysiakini.com/letters/428508

Afroz, R., Rahman, A., Masud, M.M. et al. The knowledge, awareness, attitude and motivational analysis of plastic waste and household perspective in Malaysia. Environ Sci Pollut Res 24, 2304-2315 (2017). Retrieve from https://doi.org/10.1007/s11356016-7942-0

Augustion, J. (2020). Seaweed over plastic: Indonesia's race towards sustainable packaging. Eco Business. Retrieved from https://www.eco-business.com/news/seaweed-overplastic-indonesias-race-towards-sustainable-packaging/

Chen. D. (2019). Selangor's no plastic straw policy kicks off tomorrow. New Straits Times. Retrieved from https://www.nst.com.my/news/nation/2019/06/500430/selangors-noplastic-straw-policy-kicks-tomorrow

Deva, J., McArleton, A. (2012). The Harmful Effects of Plastic on Human Health and the Environment. Retrieved from: https://www.motherearthliving.com/health-andwellness/harmful-effects-of-plastic-ze0z1205zsch

Giacovelli., C. (2018). Single-use plastics: A roadmap for sustainability. United Nations Environment Programme. Retrieved from https://wedocs.unep.org/bitstream/handle/20.500.11822/25496/singleUsePlastic_susta inability.pdf

IPSOS Malaysia. Oct 2019. Retrieved from https://www.ipsos.com/sites/default/files/201910/plastic_data_pr_-_press_release_-_english_-_211019_-_final.pdf

IPSOS Malaysia. Oct 2019 Retrieved from https://www.ipsos.com/sites/default/files/201910/plastic_data_pr_-_press_release_-_english_-_211019_-_final.pdf

Kramer, S. (2016). The one thing that makes recycling plastic work is falling apart. Retrieved from https://www.businessinsider.com/low-oil-prices-hurt-plastics-recycling-20164 ? $\mathrm{IR}=\mathrm{T}$

Kezar, K. (2018). Loliware cuts down on plastic waste with 'biodegr(edible)' cups. Dallas Business Journal Retrieved from https://www.bizjournals.com/bizwomen/news/profiles-strategies/2018/08/loliwarecuts-down-on-plastic-waste-with-biodegr.html?page=all

Liboiron, M. (2016). Redefining pollution and action: The matter of plastics. Journal of material culture, 21(1), 87-110. Retrieved from https://pdfs.semanticscholar.org/dd65/bc4317dea32a79d1306fda4f19c1972bfbef.pdf

Laville. S. (2019). Single-use plastics a serious climate change hazard, study warns. The Guardian. Retrieved from https://www.quora.com/Why-was-plastic-invented

Luo., K. (2016). Are you breathing plastic air at home? Here's how microplastics are polluting our lungs. Retrieved from https://www.weforum.org/agenda/2018/06/microplasticpollution-in-air-pollutes-our-lungs/

Reuters. (2020). Report: Malaysian Asia's biggest plastic consumers. New Straits Times. Retrieved from https://www.nst.com.my/news/nation/2020/02/566374/reportmalaysians-asias-biggest-plastic-consumers

Sörqvist., P. \& Langeborg., L. (2019). Why People Harm the Environment Although They Try to Treat It Well: An Evolutionary-Cognitive Perspective on Climate Compensation, Frontier of Psychology. Retrieved from https://www.frontiersin.org/articles/10.3389/fpsyg.2019.00348/full 
Verma, R., Vinoda, K. S., Papireddy, M., \& Gowda, A. N. S. (2016). Toxic pollutants from plastic waste-a review. Procedia Environmental Sciences, 35, 701-708.

Zakaria. B. K. (2018). Plastic thrown into oceans causing deaths of aquatic mammals. New Straits Times. https://www.nst.com.my/news/exclusive/2018/10/417648/plastic-thrown-oceanscausing-deaths-aquatic-mammals

Zen, I. S., Ahamad, R., \& Omar, W. (2013). No plastic bag campaign day in Malaysia and the policy implication. Environment, development and sustainability, 15(5), 1259-1269. Retrieved from https://www.researchgate.net/publication/257560180_No_plastic_bag_campaign_day _in_Malaysia_and_the_policy_implication 